\title{
Supervisor Behaviour and Job Stress among Bank Employees in Rivers State-Nigeria
}

\author{
Joseph Akhigbe Omoankhanlen and Martha Etakpoburho Eyakephovwan
}

\section{ABSTRACT}

\begin{abstract}
This study examined the relationship between supervisor behaviour and job stress among bank employees in Rivers State-Nigeria. The cross-sectional survey which is a type of quasi-experimental design was used because the variables were not within the researchers' control. A total population of three hundred and ten (310) employees from 17 selected deposit money banks was covered in this work. A total sample size of 169 employees used as the population. The simple random sampling technique was employed. Questionnaire was utilized to obtain necessary data from respondents. The spearman rank order correlation coefficient was used for testing the bivariate hypotheses. The findings revealed that task-oriented behaviour of supervisor had a positive significant relationship with physiological and psychological stress. Also, person oriented behaviour had a negative significant relationship with employee stress. Thus, the study concluded that task oriented and person oriented behaviour of supervisors affects the employees physiological and psychological stress which may have several effect on the health of the employees. It was thus recommended that the supervisors of the deposit money banks should avoid setting unrealistic and strenuous target for the employees as such will help reduce the psychological stress of the employees in the organization.
\end{abstract}

Keywords: Person Oriented Behaviour, Task Oriented Behaviour, Physiological Stress, Psychological Stress.
Submitted : May 06, 2021

Published : January 10, 2022

ISSN: $2507-1076$

DOI: $10.24018 /$ ejbmr.2022.7.1.879

Joseph Akhigbe Omoankhanlen * Department of Management, University of Port Harcourt, Port Harcourt, Nigeria. (e-mail:

joseph.omoankhanlen @ uniport.edu.ng) Martha Etakpoburho Eyakephovwan Department of Management, University of Port Harcourt, Port Harcourt, Nigeria. (e-mail:

martha.eyakephovwan ${ }^{\circledR}$ sterling.ng)

\section{INTRODUCTION}

The high intensity of rivalry in the business world and particularly in banking sector, has resulted in more complexity and higher workload which over the years has translated to over duty for many employees. The ever desirable quest of organization to be well-informed with the global trend and to gain competitive edge over rivals has make them to treat employees as a machine and thus neglecting the uniqueness of the employee as the key outcome of organization which is to be well nurtured to bring out their best. Employees in the organisation are the vital source of any firm and inability to effectively manage them leads to job stress which could be detrimental to individual and organizational wellbeing. It is worthy to note that stress is inevitable in the workplace. However, when the stress gets to the level beyond what the individual can bear, such could affect the effective function of the employees and organization's total productivity. Ekienabor (2016) opined that the increase in the responsibilities of employees demands that they use themselves more strenuously so as to meet up with higher work performance.

The authors maintained that the world of business is constantly subjected to rapid changes like intense competition, pressure to enhance quality and innovation, and these desires drastically increase employee's responsibilities which subsequently result in job stress (Moorhead \& Griffen, 1998). However, Benneth (1994) sees job stress as a wide collection of mental and physical symptoms that emanate from difficulties experienced employee while attempting to familiarize to an environment. A more precise definition was given by Ekienabor (2016) who defined job stress as an excessive demand which affects an employee physically and psychologically. Job stress is however a part of general stress, resulting mainly from the style of leadership and work characteristics (Wu, Li, Yao, Luo, He \& Yin, 2018). Furthermore, Antonova (2016) opined a dare need to device diverse ways to eliminate or reduce job stress because it negatively affects firms' efficiency, increase turnover rate, reduce service quality and intensify organisational cost.

Olusegun, Oluwasayo and Olawoyim (2014) identified anxiety, depression and hostility as the measures of job stress. However, Ismail, Ghani, Subhan, Joarder and Ridzuan (2015), identified two measures of job stress which include physiological stress and psychological stress. Considering the high proliferation of job stress and its undesirable consequences, it is thus paramount and imperative for supervisors to display right behaviour when dealing with employees as such could help ease their stress in the workplace. Supervisor behaviour is paramount in enhancing the psychological wellbeing of employees as it instil confidence in employees and improve their psychological 
state (Fatima \& Azam, 2016). The authors maintained that the behaviour of supervisors differs. While some are often considerate others are hostile. Uduji and Onwumere (2013) maintained that supervisor behaviour is important because it influence individual and organisational outcome. Furthermore, Gilbreath (2012) argued that supervisor behaviour does influence the morale of employees and their work behaviour. As early as 1970s, supervisor behaviour has been observed to influence psychological state of employees (Sheridan \& Vredenburgh, 1978). Similar result has been observed over the years. For instance, Stout (1984) observed that supervisor behaviour relates with health problems of workers and their emotional, physical and mental fatigue level. Thus the behaviour displayed by supervisor could affect employees either positively or negatively. Gilbreath and Benson (2004) pointed out that supervisor behaviour does influence the mental and physical health of employees. The dare need to resolve the issue of job stress has attracted the attention of several scholars. Gilbreath and Benson (2004) examined how supervisor behaviour contributes to psychological health of employees in USA. They observed a statistical significant relationship in their study. Zagross and Jamileh (2016) studied how toxic leadership relates with job stress in knowledge workers in Iran. The study observed a direct correlation between toxic leadership and job stress. Abbasi (2018) examined how leadership style relates with job stress in Pakistan. They observed direct relationship among the variables. Jaracz, Rosiak, Bertrand-Bucinska, Jaskulski, Niezurawska and Borkowska (2017) investigated how affective temperament relates with job stress. Safana, Othman and Wahab (2011) investigated if leadership practices play a significant role in job stress of teachers in Malay. They observed a significant correlation among the variables. It is interesting to note that irrespective of the various work on various variables that predict job stress, very scanty work has examined how supervisor behaviour relates with job stress among bank employees in Rivers StateNigeria. This has created a gap in literature over the years. It is this gap that has resulted into this study.

\section{StATEMENT OF PRoblem}

The problem of job stress in the deposit money banks in Nigeria has intensified in recent times. This problem has however resulted in negative work attitude and counter productive work behaviour. Job stress result in employee fatigue which ultimately affect the individual wellbeing and their productivity. Nigeria banks depend highly on their employees to render quality services to their customers which will thus enhance the customers' loyalty and commitment to the organisation. However, the manifestation of job stress truncates the capability of employees to deliver quality services to the customers. Job stress possess several cost to the organisation because it leads to poor productivity of the employees, increases occupational injury and illness, intensify workers absence from work, result in low morale in the employees and also increase health care cost, all of which could likely affect the fortune of the organisation. Furthermore, Ekinabor (2016) observed that job stress result to illness and also increases employee's time off, which negatively affects individual and the organisation. Also, Fonkeng (2013) remarked that job stress affects the firm's fortune in a negative way because it brings about low productivity and intensify dissatisfaction.

The problem of job strains further manifests in low involvement, low commitment, disloyalty and employee withdrawal. Inability of management of deposit money banks to handle the challenges of job stress will affect firm's competitiveness negatively. Organizations that are unable to eliminate or reduce the job stress of employees may not perform to the best of their ability. Despite some level of success recorded in the banking industry, there is still an issue of effectiveness as it relates with goal congruence of the member with that of the organization. While several attempts have been made over the years to alleviate job stress inside the organisation, the issue persists. Since supervisory behaviour has an effect on both the physiological and psychological well-being of workers, it is suspected that constructive supervisory behaviour can have an effect on the incidence of job stress. This study examines the relationship between supervisor behaviour and job stress among bank employees in Rivers State, Nigeria.

\section{OBJECTIVES OF THE STUDY}

The objectives are to examine the relationship between i. Task-oriented behaviour and physiological stress. ii. Task-oriented behaviour and psychological stress. iii.Person-oriented behaviour and physiological stress. iv. Person-oriented behaviour and psychological stress.

\section{RESEARCH HYPOTHESES}

THE following null hypotheses were proffered;

HO1: There is no significant relationship between taskoriented behaviour and physiological stress among banks employees in Rivers state, Nigeria.

$\mathrm{HO}$ 2: There is no significant relationship between taskoriented behaviour and psychological stress among banks employees in Rivers state, Nigeria.

HO3: There is no significant relationship between personoriented behaviour and physiological stress among banks employees in Rivers state, Nigeria.

HO4: There is no significant relationship between personoriented behaviour and psychological stress among banks employees in Rivers state, Nigeria.

\section{REVIEW OF RELEVANT LITERATURE \\ A. Theoretical Framework}

This work is founded on the person-environment fit theory. This theory assumes that stress occurs because of an incongruity between the individual and the environment (Edwards, 1998; Harrison, 1978). Thus, it is neither the person nor the situation alone that causes stress experiences and strains. There are two types of incongruity between an individual and the environment. The first type refers to the fit amongst the environmental demands and the abilities and competencies of the persons. The second type refers to the fit amongst the persons need and supplies from the environment. At the conceptual level, P-E fit theory differentiates between 
the objective and the subjective person likewise between the objective and the subjective environment (Harrison, 1978). Objective person and objective environment refer to the individual needs, abilities, and competencies and to environmental supplies and demands as they actually existthat is, independent of the person's perceptions. Subjective person and subjective environment refer to the individual's perceptions. Thus, fit may apply to the conformity of (a) the objective environment and (b) the subjective environment and (c) the subjective and objective environment (i.e., interaction with reality) and (d) the subjective and objective individual (i.e., accuracy of self-assessment).

\section{CONCEPT OF SUPERVISOR BEHAVIOUR}

Supervisors are the first level of management of organisations, where they are assigned significant roles, assignments, and obligations for forming and leading work groups (Elangovan \& Karakowsky, 1999). Ellinger, Ellinger and Keller (2005) described the supervisor as the lowest or most junior management rank, with the supervisor being accountable for the daily success of a small community. Additionally, they mentioned that a supervisor is an accomplished supervisor, a problem solver, and a community role model. Supervisors behave differently. Certain individuals are considerate, while others are not. Some bosses encourage their workers to partake in target setting, while others do not (Ramaswami, 1996). Much as superiors behave differently, discipline often has a variety of impacts on subordinates. Some subordinates resist closer oversight because they value the autonomy of the job, while others may experience increased task uncertainty in the absence of close supervision. Ellinger, Ellinger, and Keller (2005) characterized the supervisor's position as a liaison between management and organizational employees.

\section{A. Task Oriented}

In task-oriented supervision, supervisor support roles include organizing, arranging, and managing work and events for subordinates; supervisor support managers may offer technical assistance. In relational supervision, supervisor support managers are more accommodating and helpful to subordinates; they demonstrate loyalty, confidence, and a positive demeanor; and they make an effort to consider their subordinates' concerns (Yukl, 2010). Both administrators are assumed to be supervisors (Hunter, Bedell-Avers \& Mumford, 2007).

A task-oriented supervisor, to Anzalone (2017), is one who is focused on the task or set of tasks at hand, likewise all processes required to complete the task. A task-oriented supervisor is less concerned with addressing workers' personal expectations and more concerned with developing technical, step-by-step solutions to particular problems. To Anzalone, a task-oriented supervisor might suggest, "What measures will we take to achieve our quarterly financial targets?" rather than "How can we create the kind of employee productivity that results in business success?" To Anzalone, task-oriented supervisor behavior has a number of advantages. A task-oriented supervisor is extremely pragmatic and rational, with a firm grasp on how to accomplish tasks while relying on required workplace procedures. A task-oriented supervisor recognizes that a large task can require many smaller tasks; the supervisor assign work appropriately to ensure that anything is completed on schedule and efficiently.

\section{B. Person Oriented}

To Larman (2015), a person-oriented supervisor recognizes the value of assignments but devotes significant time and effort to addressing the needs of everyone participating in the assignment. This can include presenting cash rewards such as promotions, mediating organizational or classroom disputes, taking individual time with workers to hear about their talents and shortcomings, delivering aboveaverage financial benefits, or simply leading in a personable or motivating way. To Anzalone (2017), a person-oriented supervisor is focused on achieving overall results through the development of lasting partnerships with employees. While this supervisor is concerned with assignments and deadlines, he or she feels that work culture is more important. A personoriented supervisor uses relationship-building approaches such as employee appreciation and team-building drills to foster an atmosphere in which workers are valued and encouraged to participate individually in the business's growth and perform at their best. Personal-oriented supervisory behavior focuses on enhancing and improving the consistency of relationships between leaders and followers and is capable of inspiring and motivating employees to fulfill the organization's needs and objectives.

To Friedman (2013), a person-oriented management style helps to energize workers by instilling a sense of appreciation for their efforts. One primary advantages of person-oriented management is that the emphasis on employee relationships instills in workers a sense of purpose in the organization. And more successful contributions come from individuals who believe they are contributing to a company's growth. Friedman does remember, however, that supervisory behavior that is person-oriented presents a variety of difficulties.

\section{CONCEPT OF JOB STRESS}

Stress is the physical and psychological response that humans have to transitions, activities, and circumstances in their lives. Individuals feel stress in unique forms and for unique causes. The response is determined by how an individual perceives an incident or circumstance. See Selye (2012). Employment Stress is described as an emotional disturbance that is physically harmful that occurs when a job does not demand or connect with the worker's abilities, capabilities, and needs. As such, it is identified as a mental and physical challenge for a person, and even an organization.

Job stress appears in a variety of forms and leaves an impression on individuals in a variety of ways. Job pressure is a significant cause of job stress, to the demand-control model (Karasek, 1979). What separates demands from the opportunity to provide emotional security in the family is nothing other than the job.

\section{A. Physiological Stress}

When a person perceives a condition as threatening and is unable to respond appropriately, emotional, and physiological responses, often referred to as stress, are 
elicited. In psychological and medical studies, stress has been examined as a component of negative affect (Mroczek \& Almeida, 2004; Plarre et al., 2011). Given that stress will result in serious health conditions, it is critical to consider and measure stress; stress must be identified early, and individuals treated appropriately. Numerous stress markers have been established over the last two decades (Plarre et al., 2011), with physiological measurements being being the most commonly used method for identifying improvements in stress level, while facial expressions and keyboard typing patterns have also been used (Sierra, Avila, Casanova \& Pozo, 2011). Nasoz, Lisetti, and Vasilakosm (2010) created a multimodal intelligent car interface that incorporates negative affective states such as panic/fear, frustration/anger, and boredom/fatigue.

To help distinguish between stress and exhaustion, Liao, Zhang, Zhu, Ji, and Gray (2006) suggested a unifying paradigm based on a hierarchical probabilistic decisiontheoretic model that included affective state identification, active sensory action collection, and user assistance (Liao, Zhang, Zhu, Ji \& Gray, 2006). They used four distinct types of inputs: physiological responses, physical image attributes, user performance, and behavioral results, and concentrated on developing an optimized feature set rather than using all possible features to maximize recognition performance.

\section{B. Psychological Stress}

Though the symptoms of stress have garnered much interest, scholars are still unable to agree on a term. Stress, or more precisely, the stress response, are adaptive psychological and physiological changes that arise in response to environmental and psychosocial changes or challenges (stressors). Psychological stress is characterized as an external hazard that does not always elicit the usual physical "fight-or-flight" reaction, but rather induces typical stress-related psychological and physiological changes. Regardless of the response chosen (active or passive), the ability of individuals to respond to and effectively react to stress improves their longevity, reproductive capability, and, eventually, evolutionary performance. Although the stress response is necessary for survival, inability of the subject to cope with the stressor may result in psychological and physiological responses that are inadequate or inappropriate. The dynamic interplay between the three regulatory systems is disturbed in this situation, and the resulting lack of homeostasis can favor adverse health outcomes. As such, a portion of this study discusses how psychological stress affects the neuroimmunoendocrine system and, in some cases, jeopardizes an individual's wellbeing (Engel \& Schmale, 1972).

\section{EMPIRICAL FRAMEWORK}

Murali, Basit, and Hassan (2017) conducted an investigation into the effect of job stress on employee efficiency. To gather data, a causal analysis design was used. Employees from a variety of industries were selected for this reason. Prior to distributing the questionnaire via social media, a questionnaire with 26 items on the Likert Scale (1: Strongly Disagree to 5: Strongly Disagree) was established and checked for reliability and validity. A convenient sampling methodology was used to pick 310 respondents from different industries in Malaysia. The survey questionnaire was requested to be completed via Facebook inbox. The questionnaire collects demographic data and comments to assess four (4) independent variables related to stress: time constraint, workload, lack of enthusiasm, and position uncertainty. Employee output is the dependent variable. Just 136 questionnaires with completed responses were returned (usable sample). They discovered time constraints and position uncertainty affect employee success. The remaining two variables, workload, and lack of enthusiasm, have no discernible effect on employee efficiency. They hypothesized that growing time constraints and position uncertainty would result in decreased employee efficiency across the board. Thus, administrators must ensure that job uncertainty is eliminated and that specific responsibilities are assigned and conveyed to staff if they want to improve employee success. Additionally, administrators and superiors are actively advised to discuss time allocation, task completion times, and task length with their subordinates to prevent time constraints.

Sahertian and Soetjipto (2011) investigated partnershipand task-oriented leadership styles on engagement, selfefficacy, and citizenship behaviour. 125 bank respondents were surveyed. Data collection methods included questionnaires and interviews. The data where analyzed with SEM. There was no correlation between relationship-oriented and task-oriented citizenship activity. The study discovered a significant association between engagement, success, and self-efficacy. Brown (2003) examined the relationship between relational and task-oriented behaviors and employee engagement. 361 respondents were surveyed. A questionnaire was used to collect data. The data where analyzed using the Spearman coefficient. The research discovered a significant link between engagement and both relational and task-oriented action. However, relationshiporiented conduct has the greatest effect on employee engagement.

Fayyaz, Naheed, and Hasan (2014) investigated the impact of task-oriented and emotional supervisory behaviors on employee success. Data were obtained via questionnaires from 200 full-time workers, which included supervisor behavior, employee efficiency, and communicator competence. Correlation and regression were then used. The findings suggested a solid, constructive, and statistically relevant connect in supervisor communication competence, task and relationship supervisor behaviors, and employee success.

In Nigerian banks, Ayodotun, Maxwell, Oladele, Hezekiah, Taiye, and Olamide (2018) investigated how organizational environment influences task-trait leadership and employee engagement. A total of 167 respondents were successfully contacted; data collection was conducted through questionnaires. The data where analyzed using hierarchical multiple regression. The results indicated that task-oriented leadership has a significant effect on engagement.

Bronkhorst et al. (2014) conducted a comprehensive analysis of the literature to answer the following two study questions: (1) how does organizational climate impact workers' mental wellbeing conditions in health care 
organizations? and (2) what aspect of organizational climate is most closely correlated with the mental wellbeing consequences of health care employees? They used four search methods in addition to inclusion and quality assessment requirements to identify and choose qualifying studies. Twenty-one articles were included in the study. The data from the studies is compiled to establish a collection of results. The contents of the studies were reviewed and categorized to common characteristics. Reduced levels of burnout, depression, and anxiety were favorably associated with expectations of a healthy work climate. More specifically, our findings suggest that community relationships among colleagues are critical in explaining the mental wellbeing of health care staff. Additionally, evidence suggests that some aspects of supervisory action and administration influence mental health outcomes. The association regarding touch or attendance and mental health consequences was unclear.

Basiska (2008) examined the impact of job stressors on firemen's psychological well-being. A total of 121 firefighters from rescue-firefighting units is questioned. The Goldberg's GHQ 12 was used to evaluate well-being, the Dudek's PJSQ was used to assess job stress, and an index of involvement in stressful activities was used to assess engagement in traumatic events. Nineteen percent of firemen were classified as having an elevated risk of developing psychiatric illnesses. Occupational stress has an undeniable negative effect on well-being. Individuals with poor psychological well-being experienced a high degree of job stress. Work overload was the primary cause contributing to the decline in well-being. With the above in mind, reducing job stress is critical for fostering workplace mental health.

Areekkuzhiyil (2014) investigates the different factors that add to the operational stress experienced by teachers employed in the higher education field in the Indian state of Kerala. The study's data collection was made simple by interviewing 200 teachers in the higher education sector. The exploratory factor analysis revealed nine important predictors of organizational stress: interpersonal relationships within the organisation, technical and skill growth, organizational acceptance, work climate, autonomy in work, work-family engagement, position conflict, job security and remuneration, and non-academic. Therefore, it is recommended that when attempting to draft legislation and programs for teachers serving in the state's higher education system, these nine considerations be taken into account.

Thisera (2013) examined the association in supervisory behavior and subordinates' job performance; she compared the supervisory behaviors of immediate male and female supervisors. Democratic and autocratic supervisor behaviors were considered dimensions of the independent variable, while work quantity and efficiency, errors, cooperation, attendance, and work-related attitudes were considered dimensions of job success. The data collection instrument was a standardized questionnaire administered to a group of 138 female respondents who worked in organizational level positions in four chosen clothing industry organizations. The data were analyzed using the single sample t-test, correlation analysis, and mean value analysis, both of which are considered descriptive statistical methods. To statistical findings, the researcher discovered a close correlation between supervisor behavior and subordinate job success. Mean value research found that male supervisors are more autocratic, while female supervisors tend to exhibit more egalitarian supervisor behavior.

Qureshi and Hamid (2017) offer statistical justifications for the direct effect of supervisor support on job satisfaction; and fairness experience on the favorable interaction in supervisor support and job satisfaction. Increased competition in global economies, it is claimed, is compelling firms to rely on ways to contribute to the development of a much better and more competitive workforce. This is more easily accomplished when people are relaxed and fulfilled with their work. Job satisfaction has been shown to be an important indicator of a variety of organizational outcomes, including employee participation, motivation, organizational citizenship behavior, and knowledge sharing.

Sun, Buys, and Wang (2013) investigated the human and organizational influences that aid depression and stress in a large privately held company in China. Thirteen privately held retail companies in China were included in the crosssectional analysis. 4,847 workers aged 18-54 employed by the management boards of the 13 companies completed a self-report study. The chi-square test was used to compare variations in a variety of demographic factors and chronic conditions between the depressed and non-depressed classes. A logistic regression analysis determined the relationship in depression and human characteristics (work capacity and resilience) and organizational environmental characteristics. There were significant correlations between employee depression and all personal causes, likewise one organizational environmental cause. Personal factors include inability to function and a lack of stamina, while workplace factors include ethos and community. The key environmental element affecting the organization was a lack of enterprise ethos and community.

\section{Methodology}

The cross-sectional survey, a form of quasi experimental design was utilized, and the accessible population was 17 designated banks operational in Rivers state, Nigeria. The Krejcie and Morgan (1970) table was employed to arrive at a sample size of 169. Thus, 169 questionnaires were dispersed to workers in the 17 selected firms and the simple random sampling technique was used. This technique was used because it gives a true representative of the entire population and reduces the tendency for researcher bias in selecting the sample case. The independent variable (supervisor behaviour) was measured in terms of task oriented behaviour and person oriented behaviour. 5 items were used in measuring task-oriented behaviour (e.g., My immediate supervisor set standard of performance for employees) and 5 items for person oriented behaviour (e.g., My immediate supervisor show concern for the personal well-being of others). Also, the dependent variable (job stress) was measured using physiological stress and psychological stress. 5 items were used in measuring Physiological Stress (e.g., I often feel a great deal of stress because of my job) and 5 items for Psychological Stress (e.g., In my organization, my job often make me feel tired and exhausted). Items were rated on 
a 4-point Likert scale ranging from 1-strongly disagreed, 2disagree, 3-agree and 4-strongly agreed. The spearman rank order correlation coefficient statistical analysis was used in analyzing the bivariate hypotheses through the help of Statistical Package for Social Sciences (SPSS) version 21.

\section{RESUlT}

A total of 169 questionnaires was distributed to respondent, however, only 120 (71\%) copies were returned and used for the study. The hypotheses test was undertaken at a $95 \%$ confidence interval implying a 0.05 level of significance. The decision rule is set at a critical region of $p$ $>0.05$ for acceptance of the null hypothesis and $\mathrm{p}<0.05$ for rejection of the null hypothesis.

TABLE I: TASK ORIENTED BEHAVIOUR AND PHYSIOLOGICAL STRESS

\begin{tabular}{|c|c|c|c|c|}
\hline \multicolumn{5}{|c|}{ Correlations } \\
\hline & & & $\begin{array}{c}\text { Task } \\
\text { Oriented } \\
\text { Behaviour }\end{array}$ & $\begin{array}{c}\text { Physiologica } \\
\text { Stress }\end{array}$ \\
\hline \multirow{6}{*}{$\begin{array}{c}\text { Spearman's } \\
\text { rho }\end{array}$} & \multirow{3}{*}{$\begin{array}{c}\text { Task Oriented } \\
\text { Behaviour }\end{array}$} & $\begin{array}{l}\text { Correlation } \\
\text { Coefficient }\end{array}$ & 1.000 & 0.131 \\
\hline & & Sig. (2-tailed) & & 0.003 \\
\hline & & $\mathrm{N}$ & 120 & 120 \\
\hline & \multirow{3}{*}{$\begin{array}{c}\text { Physiological } \\
\text { Stress }\end{array}$} & $\begin{array}{l}\text { Correlation } \\
\text { Coefficient }\end{array}$ & 0.131 & 1.000 \\
\hline & & Sig. (2-tailed) & 0.003 & \\
\hline & & $\mathrm{N}$ & 120 & 120 \\
\hline
\end{tabular}

The result of the analysis in Table I shows a significant level $p<0.05(0.003<0.05)$, rho $=0.131$ between Task Oriented Behaviour and Physiological Stress. This denotes a substantial negative link amongst Task Oriented Behaviour and Physiological Stress. The null hypothesis was rejected, and alternate hypothesis accepted.

\begin{tabular}{|c|c|c|c|c|}
\hline \multicolumn{5}{|c|}{ Correlations } \\
\hline & & & $\begin{array}{c}\text { Task } \\
\text { Oriented } \\
\text { Behaviour }\end{array}$ & $\begin{array}{c}\text { Psychological } \\
\text { Stress }\end{array}$ \\
\hline \multirow{6}{*}{$\begin{array}{l}\text { Spearman's } \\
\text { rho }\end{array}$} & \multirow{3}{*}{$\begin{array}{c}\text { Task Oriented } \\
\text { Behaviour }\end{array}$} & $\begin{array}{l}\text { Correlation } \\
\text { Coefficient }\end{array}$ & 1.000 & 0.199 \\
\hline & & Sig. (2-tailed) & & 0.029 \\
\hline & & $\mathrm{N}$ & 120 & 120 \\
\hline & \multirow{3}{*}{$\begin{array}{c}\text { Psychological } \\
\text { Stress }\end{array}$} & $\begin{array}{l}\text { Correlation } \\
\text { Coefficient }\end{array}$ & 0.199 & 1.000 \\
\hline & & Sig. (2-tailed) & 0.029 & \\
\hline & & $\mathrm{N}$ & 120 & 120 \\
\hline
\end{tabular}

The outcome of the analysis in Table II shows a significant level $p<0.05(0.029<0.05)$, rho $=-0.199$ between Task Oriented Behaviour and Psychological Stress. This shows a noteworthy relationship amongst Task Oriented Behaviour and Physiological Stress. The null hypothesis was rejected, and the alternate hypothesis accepted.

TABLE III: PERSON ORIENTED BEHAVIOUR AND PHYSIOLOGICAL STRESS Correlations

\begin{tabular}{|c|c|c|c|c|}
\hline \multicolumn{5}{|c|}{ Correlations } \\
\hline & & & $\begin{array}{c}\text { Person } \\
\text { Oriented } \\
\text { Behaviour }\end{array}$ & $\begin{array}{c}\text { Physiological } \\
\text { Stress }\end{array}$ \\
\hline \multirow{6}{*}{$\begin{array}{l}\text { Spearman's } \\
\text { rho }\end{array}$} & \multirow{3}{*}{$\begin{array}{c}\text { Person Oriented } \\
\text { Behaviour }\end{array}$} & $\begin{array}{l}\text { Correlation } \\
\text { Coefficient }\end{array}$ & 1.000 & -0.351 \\
\hline & & Sig. (2-tailed) & & 0.000 \\
\hline & & $\mathrm{N}$ & 120 & 120 \\
\hline & \multirow{3}{*}{$\begin{array}{l}\text { Physiological } \\
\text { Stress }\end{array}$} & $\begin{array}{l}\text { Correlation } \\
\text { Coefficient }\end{array}$ & -0.351 & 1.000 \\
\hline & & Sig. (2-tailed) & 0.000 & \\
\hline & & $\mathrm{N}$ & 120 & 120 \\
\hline
\end{tabular}

The outcome in Table III shows a significant level $p<0.05$ $(0.000<0.05)$, rho $=-0.351$ between Person Oriented Behaviour and Physiological Stress. This indicates a significant negative link amongst Person Oriented Behaviour and Physiological Stress. This means if the supervisor is person-oriented, the physiological stress of the workers will be reduced.

TABLE IV: PERSON ORIENTED BEHAVIOUR AND PSYCHOLOGICAL STRESS

\begin{tabular}{|c|c|c|c|c|}
\hline \multicolumn{5}{|c|}{ Correlations } \\
\hline & & & $\begin{array}{c}\text { Person } \\
\text { Oriented } \\
\text { Behaviour }\end{array}$ & $\begin{array}{c}\text { Psychological } \\
\text { Stress }\end{array}$ \\
\hline \multirow{6}{*}{$\begin{array}{l}\text { Spearman's } \\
\text { rho }\end{array}$} & \multirow{3}{*}{$\begin{array}{l}\text { Person Oriented } \\
\text { Behaviour }\end{array}$} & $\begin{array}{l}\text { Correlation } \\
\text { Coefficient }\end{array}$ & 1.000 & -0.266 \\
\hline & & Sig. (2-tailed) & & 0.003 \\
\hline & & $\mathrm{N}$ & 120 & 120 \\
\hline & \multirow{3}{*}{$\begin{array}{l}\text { Psychological } \\
\text { Stress }\end{array}$} & $\begin{array}{l}\text { Correlation } \\
\text { Coefficient }\end{array}$ & -0.266 & 1.000 \\
\hline & & Sig. (2-tailed) & 0.003 & \\
\hline & & $\mathrm{N}$ & 120 & 120 \\
\hline
\end{tabular}

The outcome in Table IV shows a significant level $p>0.05$ (0.003> 0.05), rho $=-0.266$ between Person Oriented Behaviour and Psychological Stress. This denotes a substantial negative association amongst Person Oriented Behaviour and Psychological Stress. This entails that personoriented form of behaviour will lead to less psychological stress. The null hypothesis was rejected, and alternate hypothesis was accepted.

\section{DISCUSSION OF FINDINGS}

\section{A. Task Oriented Behaviour and Physiological Stress}

The bivariate hypotheses between Task Oriented Behaviour and Physiological Stress demonstrate a significant association between the two variables. The result indicated that the $\mathrm{p}$-value for Task Oriented Behaviour was less than $0.05(\mathrm{p}=0.0030 .05)$, implying that it has a significant association with Physiological Stress. Correlation coefficients (rho) were 0.131. As a result, a significant association exists between Task-Oriented Behaviour and Physiological Stress. Thus, increasing Task-Oriented Behaviour may contribute to an increase in Physiological Stress. Thus, the study's initial goal of determining whether Task-Oriented Behaviour is associated with Job Stress was met. These studies corroborate Fayyaz, Naheed, and Hasan's (2014) observation that task-oriented supervisor behaviour results in physiological stress.

\section{B. Task Oriented Behaviour and Psychological Stress}

The conclusion of the hypothesis two test showed that there is a significant association between Task Oriented Behaviour and Psychological Stress. The P-value of 0.029, which is smaller than the 0.05 degree of meaning $(p=0.0290 .05)$, indicates a positive relationship between Task Oriented Behaviour and Psychological Stress. Rho values of 0.199 substantiated this. This indicates that there is a tenuous positive correlation between task-oriented behaviour and psychological stress in the workplace. The more task-oriented the behavior, the greater the psychological stress, and vice versa. This research corroborates Basiska's (2008) finding that Task-Oriented Behaviour raises Psychological Stress. 


\section{Person Oriented Behaviour and Physiological Stress}

As the bivariate regression for hypothesis three is performed, it can be shown that the significance value of 0.000 was smaller than the 0.05 significance mark $(p=0.0000 .05)$. This indicates a strong relationship between Person-Oriented Behaviour and Physiological Stress. The rho value indicates a -0.351 association between Person Oriented Behaviour and Physiological Stress. This indicates the existence of a major beneficial association between PersonOriented Behaviour and Physiological Stress. This indicates a moderately negative and important association between Person Oriented Behaviour and Physiological Stress. If the supervisor is person-oriented, the workers' physiological stress will be reduced; if the supervisor is not, the workers' physiological stress will increase. These results corroborate Murali, Basit, and Hassan's (2017) finding that PersonOriented Behaviour has a strong negative association with Physiological Stress.

\section{Person Oriented Behaviour and Psychological Stress}

The study of hypothesis four reveals a significant negative correlation between Person Oriented Behaviour and Psychological Stress. This is since P-values of 0.003 are smaller than the threshold of importance of 0.05 ( $\mathrm{p}=0.0030 .05$ ). As a result, the null hypothesis is ruled out. This implies that psychological stress is inversely proportional to person-oriented behaviour. The correlation coefficient (rho) indicates that Person Oriented Behaviour has a -0.266 correlation with Psychological Stress. If the supervisor is person-oriented, psychological stress among employees is reduced; but, if the supervisor is not, physiological stress increases. These results corroborate Murali, Basit, and Hassan (2017) findings that a supervisor who is person oriented reduces workers' psychological stress.

\section{CONCLUSION AND RECOMMENDATIONS}

Organizations are target-oriented, and to increase staff morale and the organization's goal fulfilment, job stress for workers must be kept to a minimum, since this would contribute to their overall well-being and therefore to the firm's competitiveness. To the study's conclusions, the supervisor's task-oriented behaviour has a statistically important association with physiological stress in the organisation. This means that an increase in task-oriented behaviour among bank employees results in an increase in physiological stress. When the supervisor of a company is constantly focused on task completion without regard for the employees' well-being, this creates physiological stress in employees, which can have a detrimental effect on them and on the organization's performance. Additionally, managers' task-oriented behaviour has a favourable association with psychological stress. When supervisors in the banking industry are defined by an initiating structure, this results in increased supervisor anxiety, depression, fatigue, and anger. Again, supervisors' person-oriented behaviour has a negative correlation with physiological and psychological stress. This inverse relationship demonstrates that as individualistic behaviour increases, physiological and psychological stress decreases. Enhancing person-centred behaviour can potentially result in decreased organizational stress. In conclusion, supervisors' task- and person-oriented behaviour has an impact on workers' physiological and psychological stress, which may have a number of negative consequences for their health and well-being. As a result of the study's findings, the following recommendations are made:

1) The supervisors of the deposit money banks should ensure that employees wellbeing is given optimum priority in all circumstances as such will help lessen stress psychologically in organization.

2) The supervisor of the deposit money banks should avoid setting unrealistic and strenuous target for the employees as such will help reduce the psychological stress.

3) The supervisor of the deposit money banks should create a work environment in which the employees find fun when carrying out their duty in the organization, such will help enhance their psychological being and reduce the inducement of stress in the organization.

4) The supervisor of the deposit money banks should exhibit positive behaviours by acting friendly towards all group members as such will enhance lessen stress among employees.

\section{REFERENCES}

Abbasi, S. G. (2018). Leadership styles: Moderating impact on job stress and health. Journal of Human Resources Management Research, 20, (18), $2-11$.

Antonova, E. (2016). Occupational stress, job satisfaction and employee loyalty in hospitality industry: A comparative case study of two hotels in Russia. Master thesis in International tourism, Modulvienna University.

Anzalone, C. (2017) Differences Between Task-Oriented Leaders \& Relational-Oriented Leaders. Retrieved December 26, 2019, from http://smallbusiness.chron.com/differences-betweentaskorientedleaders relationaloriented-leaders-35998.html

Areekkuzhiyil, S. (2014). Factors Influencing the Organizational Stress among Teachers Working in Higher Education Sector in Kerala: An Empirical Analysis, Research and Pedagogic Interventions, 2(2).

Ayodotun, I. S., Maxwell, O. A., Oladele, K. J., Hezekiah, F. O., Taiye, B. T. \& Olamide, O. (2018). Moderating effect of organizational climate on a task-trait leadership orientation and employee commitment: The Nigerian banking experience. Academy of Strategic Management Journal, 17(2), $1-6$.

Basińska, B. (2008). The effect of job-related stress on psychological wellbeing. $\quad$ Retrieved from https://www.researchgate.net/publication/245023194.

Bennett, R. (1994). Organisational behaviour, $2^{\text {nd }}$ edition, London, Pitman publishing.

Bronkhorst. B., Tummers,L. Steijn, B. \& Vijverberg, D. (2014). Organizational Climate and Employee Mental Health Outcomes: A Systematic Review of Studies in Health Care Organizations, Health Care Management Review, 1-42.

Brown, B. B. (2003). Employees' organizational commitment and their perception of supervisors' relations-oriented and task-oriented leadership behaviours. Unpublished doctoral dissertation, Virginia Polytechnic Institute and State University, Virginia.

Edwards, J. R. (1998). Cybernetic theory of stress, coping, and wellbeing. In C. L. Cooper (Ed.), Theories of organizational stress (pp. 122-152). Oxford, England: Oxford University Press.

Ekienabor, E. E. (2016). Impact of job stress on employees' productivity and commitment. International Journal for Research in Business, Management and Accounting, 2(5), 124-133.

Elangovan, A.R., \& Karakowsky, L. (1999), The role of trainee and environmental factors in transfer of training: an exploratory framework, Leadership and Organization Development Journal, 20(4), 268-275.

Ellinger, A.E., Ellinger, A.D., \& Keller, S.B. (2005), Supervisory coaching in a logistics context, International Journal of Physical Distribution \& Logistics Management, 35 (9), 620-636.

Engel, G. L. \& Schmale, A. H. (1972). Conservation withdrawal: a primary regulatory process for organismic homeostasis. Ciba Found Symp; 8 , $57-75$. 
Fatima, Z. \& Azam, M. K. (2016). Consequences of supervisory behaviour. A literature review. IJBIT, 9(2), 33-39.

Fayyaz, H., Naheed, F. \& Hasan, A. (2014). Effect of Task Oriented and Relational Leadership Style on Employee Performance; Moderating Impact of Communicator Competence, Journal of Marketing and Consumer Research, 3, 1-9.

Fonkeng, C. (2018). Effects of job stress on employee performance in an enterprise: A microfinance institution in Cameroon. Unpublished master dissertation, Centria University of Applied Sciences.

Friedman, E. (2013), Task-Oriented vs. People-Oriented Management Styles: Which is Better? Retrieved December 26, 2019, from http://blog.eskill.com/task-people-oriented-management/.

Gilbreath, B. \& Benson, P.G. (2004). The contribution of supervisor behaviour to employee psychological well-being, Work \& Stress, 18(3), 1-12.

Gilbreath, B. (2012). Supervisor behaviour and employee presenteeism. International journal of leadership studies, 7(1), 114-131.

Harrison, R. V. (1978). Person-environment fit and job stress. InC. L. Cooper \& R. Paye (Eds.), Stress at work (pp. 175-205). New York: Wiley.

Hunter, S. T., Bedell-Aver, K. E., \& Mumford, M. D. (2007). The Typical Leadership Study: Assumptions, implications, and potential remedies. The Leadership Quarterly, 18,435-446.

Ismail, A., Ghani, A. B. A., Subhan, M., Joarder, M. H. R. \& Ridzuan, A. A. (2015). The relationship between stress and job satisfaction: An evidence from Makysian peacekeeping mission. Mediterranean journal of social sciences, 6(4), 647-655.

Jaracz, M., Rosiak, I., Bertrand-Bucinska, A., Jaskulski, M., Niezurawska, J. \& Borkowska, A. (2017). Affective temperament, job stress and professional burnout in nurses and civil servants. Plos one 12(6), $1-$ 11.

Karasek, R. (1979). Job demands, job decision latitude, and mental strain: Implications for job redesign. Administrative Science Quarterly, 24, 285-306.

Krejcie, R. V. \& Morgan, D. W. (1970). Determining sample size for research activities. Educational and Psychological Measurement, 30, 607-610.

Larman, A. (2015). Task-Oriented Vs People-Oriented Leadership Styles. Retrieved December 26, 2019, from http://ezinearticles.com/?TaskOriented-Vs-People-Oriented-Leadership-Styles\&id=9253531.

Liao, W., Zhang, W., Zhu, Z., Ji, Q. \& Gray, W. (2006). Toward a decisiontheoretic framework for affect recognition and user assistance, Int. J. of Human-Computer Studies, 64(9), 847-873.

Moorhead, H. \& Griffen, F. (1998). Organisational behaviour. Boston, Houghton Mifflin Company.

Mroczek, D. \& Almeida, D. (2004). The effect of daily stress, personality, and age on daily negative affect, J. of Personality, 72(2), 355-378.

Murali, S.B., Basit, A. \& Hassan, Z. (2017). Impact of Job Stress on Employee Performance, International Journal of Accounting \& Business Management, 5(2), 13-33.

Nasoz, F., Lisetti, C. \& Vasilakosm, A. (2010). Affectively intelligent and adaptive car interfaces," Information Science, 180(20), 3817-3836.

Olusegun, A. J., Oluwasayo, A. J. \& Olawoyim, O. (2014). An overview of the effects of job stress on employees performance in Nigeria tertiary hospitals. Scientific review article, 60(4), 139-153.

Plarre, K., Raij, A., Hossain, S., Ali, A., Nakajima, M., Al'absi, M., Ertin, E., Kamarck, T., Kumar, S., Scott, M., Siewiorek, D., Smailagic, A. \& Wittmers, L. (2011). Continuous inference of psychological stress from sensory measurements collected in the natural environment, In Proc. 10th Int. Conf. on Information Processing in Sensor Networks (IPSN), 97-108.

Qureshi, M.A. \& Hamid, K. (2017). Impact of Supervisor Support on Job Satisfaction: A Moderating role of Fairness Perception, International Journal of Academic Research in Business and Social Sciences, 7(3), 235-242.

Ramaswami, S. N., (1996). Marketing Controls and Dysfunctional Employee Behaviors: A Test of Traditional and Contingency Theory Postulates. Journal of Marketing, 60 (2), 105-120.

Safana, T., Othman, A. B. \& Wahab, M. N. A. (2011). The role of leadership practices on job stress among Malay academic staff. A structural equation modelling analysis. International educational studies, 4(1), 90-100.

Sahertian, P. \& Soetjipto, B. E. (2011). Improving employee's organizational commitment, self-efficacy and organizational citizenship behavior through the implementation of task-oriented and relationship-oriented leadership behavior.

Selye, H. (2012). The stress of life. New York: McGraw-Hill.

Sharidan, J. E. \& Vredenburgh, D. J. (1978). Usefulness of leadership behaviour and social power variables in predicting job tension, performance and turnover of nursing employees. Journal of applied psychology, 63, 89-95.
Sierra, A., Avila, C., Casanova, J. \& Pozo, G., (2011). A stress-detection system based on physiological signals and fuzzy logic, IEEE Trans. Industrial Electronics, 58(10), 48574865.

Stout, J. K. (1984). Supervisors structuring and consideration behaviours and workers' job satisfaction, stress and health problems. Rehabilitation Bulletin, 110, 67-85.

Sun, J., Buys, N. \& Wang, X. (2013). Depression in Employees in Privately Owned Enterprises in China: Is It Related to Work Environment and Work Ability? International Journal of Environmental Research and Public Health, 10, 1152-1167.

Thisera. T.J.R. (2013). Exploring The Relationship Between Supervisor's Leadership and Subordinates' Performance, International Journal of Social Science \& Interdisciplinary Research, 2 (6), 176-185.

Uduji, J. I. \& Onwumere, J. U. J. (2013). Supervisory behaviour and salesforce performance: An empirical investigation. Developing Country Studies, 3, 6-13

Wu, X., Li, Y., Yao, X., He, X. \& Yin, W. (2018). Development of construction workers job stress scale to study and the relationship between job stress and safety behaviour: An empirical study in Beijing. International journal of environmental research and public health, 15 $1-12$.

Yukl, G. (2010). Leadership in Organization (7th Edition). South Asia, Pearson Education, Inc.

Zagross, H. \& Jamileh, Z. (2016). Relationship between toxic leadership and job stress of knowledge workers. Studies in Business and Economics, 11(3), 84-89.

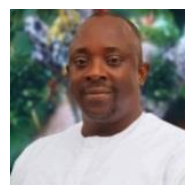

Omoankhanlen Joseph Akhigbe, Ph.D. is an Associate Professor of Management at the Department of Management, University of Port Harcourt, Port Harcourt - Nigeria. He received his $\mathrm{PhD}$ (Business Management; April, 2010); M.Sc (Business Management; September, 2006) both from Ebonyi State University (EBSU), Abakaliki, Ebonyi State -Nigeria; B.Sc (Business Administration; July 2004); Diploma (Banking \& Finance; May 2000) both from Ambrose All University, Ekpoma Edo State -Nigeria. He has been working as a university lecturer since 2004. His teaching and research experience span across three Nigerian Public Universities [Ebonyi State University - Abakaliki (20042005), Ambrose Alli University, Ekpoma - Edo State (2006 - 2011) and University of Port Harcourt - Rivers State (2012-till date)]. Dr Akhigbe is a Member of the prestigious Academy of Management Nigeria (MTAMN) and Graduate Member of Nigerian Institute of Management (NIM). He was the best graduating student of the Faculty of Social Sciences, Ambrose Alli University Ekpoma Nigeria in 2002/2003 Academic Session with CGPA of 4.10 points on 5-point scale. He has published widely in over fifty (60) local and international journals of which many of them are in high impact factor journals.

Eyakephovwan Martha Etakpoburho is a Master Student of Management in the Department of Management, University of Port Harcourt, Port Harcourt - Nigeria. 